\title{
sciendo
}

\section{Set-to-set Performance Variation in Tennis Grand Slams: Play with Consistency and Risks}

\author{
by

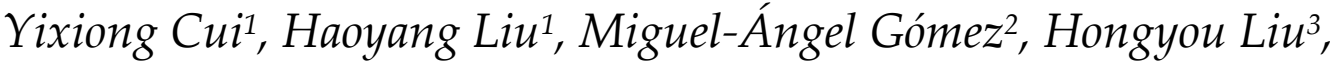 \\ Bruno Gonçalves ${ }^{4}$
}

\begin{abstract}
The study analysed the set-to-set variation in performance using match statistics of 146 completed main-draw matches in Australian Open and US Open 2016-2017 men's singles. Comparisons of technical-tactical and physical performance variables were done between different sets; and the within-match coefficients of variation $(\mathrm{CV})$ of these variables were contrasted between match winning and losing players. All comparisons were realized via standardized (Cohen's d) mean differences and uncertainty in the true differences was assessed using non-clinical magnitude-based inferences. Results showed that there was possibly to very likely decreases in the serve, net and running related variables (mean difference, $\pm 90 \%$ CL: $-0.16, \pm 0.14$ to $-0.45, \pm 0.24$, small) and an increase in the return and winner related variables $(0.17, \pm 0.24$ to $0.24, \pm 0.14$, small $)$ in the last sets when compared to the initial sets, indicating the influence of match fatigue and the player's choice of match tactics and pacing strategy. Besides, winning players were revealed to have lower $C V$ values in most of performance variables $(-0.16, \pm 0.24$ to $-0.82, \pm 0.23$, small to moderate) except for the second serve, winner, and physical performance variables $(0.25, \pm 0.26$ to $1.6, \pm 0.25$, small to large), indicating that they would sacrifice the consistency to gain more aggressiveness and to dominate the match.
\end{abstract}

Key words: performance profile, match statistics, analysis, winner.

\section{Introduction}

The complexity and dynamics of tennis determine that player's game strategy and technical-tactical performance are critically influenced by a range of contextual constraints (Filipcic et al., 2017; Ojala and Häkkinen, 2013; Pereira et al., 2018). The available research already evidenced that those constraints might originated from the differences of the match location (O'Donoghue and Ingram, 2001), players' qualities (Cui et al., 2017, 2019), weather conditions (Morante and Brotherhood, 2007), score-line (O'Donoghue, 2012), spatial-temporal relationships among players (Carvalho et al., 2013; Martinez-Gallego et al., 2013), physiological fatigue (Gomes et al., 2011; Reid and Duffield,
2014), noise of the audience (Dube and Tatz, 1991) and even the line-calling bias (Carboch et al., 2016). Therefore, adjusting to the constant change of those constraints and making correspondent tactical decisions should be an essential attribute reinforced in the development of professional tennis players (Murray and Hunfalvay, 2017; Triolet et al., 2013).

Players are required to perceive, interpret and anticipate the before-mentioned factors efficiently and react with proper techniques (Cowden, 2016; Murray and Hunfalvay, 2017). However, it is difficult to maintain consistently this ability under a highly intensive and competitive match situation, given that their

1 - AI Sports Engineering Lab, School of Sports Engineering, Beijing Sport University, Beijing, China.

2 - Facultad de Actividad Física y del Deporte (INEF),Universidad Politécnica de Madrid, Madrid, Spain.

3 - School of Physical Education E Sports Science, South China Normal University, Guangzhou, China.

${ }^{4}$ - Department of Sport and Health, University of Évora, Évora, Portugal. 
physical and physiological status is significantly impaired by match fatigue (Davey et al., 2002; Gomes et al., 2011; Hornery et al., 2007). Consequently, it would seem to be of interest for coaches, fitness trainers and players to customize training routines and refine match strategies if more game-based evidence is unveiled.

However, most existing literature exclusively focused on the general match performance of players (Ma et al., 2013; Reid et al., 2016), failing to evaluate how different technical, tactical and physical variables changed within prolonged time or days. In light of this issue, some attempts were made to assess how players' physiological and technical performance was influenced during a simulated tournament (Gescheit et al., 2015, 2016; Ojala and Häkkinen, 2013), which showed that their technical, physical, physiological and perceptual status was compromised over consecutive days of the tournament due to heavy speed strength loads, muscle damage, and neuromuscular and perceptual fatigue. Moreover, Whiteside and Reid (2016a) measured the physical responses of professional players during the first week of Australian Open, providing the first-handed feedback of the external hitting and movement workloads within the most onerous Grand Slam tournament.

The former research inspected how performance changed within different competitive tournaments and match locations, which could be regarded as a meso-level factor that influences players' performance (De Bosscher et al., 2006). Nonetheless, few studies have analysed the variation in performance at a microlevel, which denotes for the set/game-based interrelationship between two competing players in terms of relative quality (Cui et al., 2018; Klaassen and Magnus, 2001), actual match strategy and tactics (O'Donoghue and Ingram, 2001) and positioning dynamics during the point (Carvalho et al., 2013). Knowing this variation in performance would provide more evidence of how players could maintain constant performance or experience fluctuations in certain aspects during the course of the match. Additionally, it also facilitates a deeper understanding about their tactical behaviors as well as physiological and mental state at an individual nano-level (Cowden, 2016; Gescheit et al., 2016). In turn, athletes who are conscious of their performance variation could eventually achieve greater consistency in performance and better adaptation to complex match constraints through well-oriented training (Seifert et al., 2013).

Therefore, the aims of the current study were: (i) to analyse the set-based differences in technical-tactical and physical performance of professional male players during hard-court Grand Slams; and (ii) to explore the within-player set-to-set variation in performance considering the match outcome. It was hypothesized that there would be a decrement in match performance from the first to the final set; and that the winning player would show less variation in performance than losing players.

\section{Methods}

\section{Sample and variables}

Set-level statistics of 146 completed main draw matches from 2016-2017 US Open (US) and Australian Open (AO) men's singles were included (in total 292 player observations). Performance variables were collected from the corresponding official website of each tournament. Matches that had an early withdrawal of player were excluded, and as men's singles were played by the rule of "Best-ofFive", all the matches concluding in three, four and five sets were considered. In total, there were 543 individual sets collected. This investigation was approved by Institutional Research Ethics Committee of the Beijing Sport University and conformed to the recommendations of the Declaration of Helsinki.

Twenty-three match variables collected were grouped into the serve, return and efficiency \& physical performance related categories. Raw data of some match variables were standardized into their correspondent ratios to avoid bias arising from non-uniformity. The serve performance group included: ace $\%$, serve winner $\%$, double fault $\%$, $1^{\text {st }}$ serve in $\%$, $1^{\text {st }}$ serve won $\%$, $2^{\text {nd }}$ serve won $\%$, peak serve speed $(\mathrm{km} / \mathrm{h}), 1^{\text {st }}$ serve average speed $(\mathrm{km} / \mathrm{h})$ and second serve average speed $(\mathrm{km} / \mathrm{h})$; the return performance group was comprised by: return winner\%, return unforced error $\%$, return $1^{\text {st }}$ serve won $\%$, return $2^{\text {nd }}$ serve won $\%$, break points per return game, break point won $\%$ and break point saved\%; while efficiency and physical group consisted of: winner of total points won\%, winner per unforced error ratio, 
dominance ratio, net points won $\%$, net points won of total points won\%, total distance covered in a set $(\mathrm{m})$ and distance covered per point $(\mathrm{m})$.

The serve speed is measured by a radar system that was tested to have acceptable precision (average absolute measure difference: $0.8 \%$ ) (ITF, 2005), while the distance related data are provided by the Hawk-Eye system that is used to track player's movement every $40 \mathrm{~ms}$ with a reported measurement mean error of $3.6 \mathrm{~mm}$ (Mecheri et al., 2016). To test the inter-operator reliability of the collected data, two performance analysts in tennis collected the data of two randomly-selected matches from US and AO. Later, the inter-operator and operators vs. official websites comparisons were realized for the notational variables (excluding serve speed and distance related variables). The result of the intraclass correlation coefficients (ICC) was 1 and of standardized typical errors (TE) was 0 for: aces\%, double faults $\%$, $1^{\text {st }}$ server in $\%$, $1^{\text {st }}$ serve won $\%$, $2^{\text {nd }}$ serve won $\%$, return $1^{\text {st }}$ serve won $\%$, return $2^{\text {nd }}$ serve won $\%$, break point per return game, break point $w o n \%$, break point saved $\%$, and dominance ratio; while the ICC ranged from 0.76 to 0.99 , and TE varied from 0.11 to 0.46 for: serve winner\%, return winner\%, return unforced error\%, net point won $\%$, net points won of total points won $\%$, winner per unforced error ratio, and winner of total points won\%. The results showed good to excellent reliability for all variables tested (Hopkins, 2000).

\section{Statistical analysis}

Descriptive statistics for each of the performance variable was calculated and presented as means with standard deviations (SD). In the first place, a repeated measures analysis of variance (ANOVA) was conducted to analyse the effect of different sets on players' performance, with partial eta squared $\left(\eta^{2}\right)$ applied as the effect size estimate (alpha level set at 0.05). Afterwards, post-hoc pairwise analysis was done between each set by calculating standardized (Cohen's d) mean differences, computed with pooled variance and respective $90 \%$ confidence intervals (Hopkins et al., 2009). Next, a comparison of set-to-set variation in performance was done between winning and losing players of the matches. This was achieved through the contrast of the coefficient of variations $(\mathrm{CV})$ of all performance variables within all the sets. The comparison was also performed via standardized (Cohen's d) mean differences with $90 \%$ confidence intervals (Hopkins et al., 2009). The difference within each pair of comparison was expressed as a factor of the smallest worthwhile difference, based on a small standardized effect of Cohen's d effect-size principle $(0.2 \times$ between-sets SD). Thresholds for effect size statistics were 0.2 , trivial; 0.6 , small; 1.2 , moderate; 2.0, large; and $>2.0$, very large. Uncertainty in the true differences of the comparisons was assessed using non-clinical magnitude-based inferences. Magnitudes of clear effects were described according to the following scale: $25-75 \%$, possibly; $75-95 \%$, likely; $95-99 \%$, very likely; .99\%, most likely (Hopkins et al., 2009). Differences were deemed clear if $90 \%$ CL for the difference in the means did not overlap substantial positive and negative values (Hopkins, 2007).

\section{Results}

Table 1 shows the match performance variables within five sets and the repeated measures ANOVA results. Figure 1 presents the results of inter-sets comparisons of these variables (standardized Cohen's d units with 90\% confidence interval). Compared to the first and the second set, there were: i) possibly to very likely decreases in serve winner $\%, 1^{\text {st }}$ serve won $\%$, $2^{\text {nd }}$ serve won $\%$, serve speeds, double fault $\%$, return unforced error $\%$, break point saved $\%$ and dominance ratio when playing in the $3^{\text {rd }}$ to $5^{\text {th }}$ set, especially in the $4^{\text {th }}$ and $5^{\text {th }}$ set; ii) possibly increases in $1^{\text {st }}$ serve in $\%$, return $2^{\text {nd }}$ serve won $\%$ and break point won $\%$ in the $5^{\text {th }}$ set; iii) possibly to likely increases in net success of total point won $\%$ in $2^{\text {nd }}, 3^{\text {rd }}$ and $5^{\text {th }}$ set; iv) possibly increases in return winner\%, return $1^{\text {st }}$ won $\%$ and winner per unforced error ratio in the $4^{\text {th }}$ and $5^{\text {th }}$ set; $v$ ) running distance was possibly higher in the $4^{\text {th }}$ and $5^{\text {th }}$ set. All the above results presented a small effect size.

Figure 2 illustrated the descriptive statistics of set-to-set CVs of performance variables for winning and losing players, and the results of comparisons between them. It was shown that winning players had possibly to very likely higher $\mathrm{CV}$ s in double fault $\%, 1^{\text {st }}$ serve in $\%, 2^{\text {nd }}$ average serve speed, return winner\%, return UE\%, winner per unforced error ratio, dominance ratio, and running distance than the latter, with a small to 
moderate magnitude effect; while the match losers presented possibly to most likely higher CVs in ace $\%$, serve winner $\%, 1^{\text {st }}$ and $2^{\text {nd }}$ serve won $\%, 1^{\text {st }}$ and $2^{\text {nd }}$ return point won $\%$, winner of total point won $\%$ and especially in break-point related variables: break point per return game, and break point won\% than winners, with moderate to large magnitude effects. Only trivial differences were found in serve speed and net point performance related variables.

Table 1

Match performance of male tennis players within different sets during hard-court Grand Slams

\begin{tabular}{|c|c|c|c|c|c|c|c|c|}
\hline Set No. & $\begin{array}{l}1^{\text {st }} \text { Set } \\
(n=292)\end{array}$ & $\begin{array}{l}2^{\text {nd }} \text { Set } \\
(n=294)\end{array}$ & $\begin{array}{l}3^{\text {rd }} \text { Set } \\
(n=294)\end{array}$ & $\begin{array}{l}4^{\text {th }} \text { Set } \\
(n=150)\end{array}$ & $\begin{array}{l}5^{\text {th }} \text { Set } \\
(n=56)\end{array}$ & $\mathrm{F}$ & $p$ & $\eta^{2}$ \\
\hline Ace $\%$ & $9.0(7.2)$ & $8.3(7.4)$ & $8.6(7.7)$ & $8.6(8.3)$ & $8.3(7.0)$ & 0.373 & 0.82 & 0.001 \\
\hline Serve winner\% & $2.2(3.2)$ & $1.8(2.8)$ & $1.6(2.3)$ & $1.5(2.4)$ & $1.6(2.5)$ & 2.979 & 0.02 & 0.01 \\
\hline Double fault $\%$ & $10.9(9.7)$ & $10.5(10.0)$ & $11.8(10.7)$ & $10.2(9.7)$ & $10.1(10.7)$ & 0.860 & 0.49 & 0.003 \\
\hline $1^{\text {st }}$ serve in $\%$ & $59.5(10.6)$ & $59.4(11.1)$ & $59.8(11.1)$ & $58.9(10.1)$ & $61.1(9.9)$ & 0.502 & 0.74 & 0.002 \\
\hline $1^{\text {st }}$ serve won $\%$ & $73.4(12.8)$ & $71.8(14.2)$ & $73.1(13.3)$ & $70.4(13.4)$ & $71.8(11.7)$ & 1.592 & 0.17 & 0.006 \\
\hline $2^{\text {nd }}$ serve won $\%$ & $51.7(16.9)$ & 50.7 (17.5) & $50.5(16.4)$ & $49.9(17.9)$ & $47.9(16.2)$ & 0.736 & 0.57 & 0.003 \\
\hline $\begin{array}{l}\text { Fastest Serve Speed } \\
(\mathrm{km} / \mathrm{h})\end{array}$ & $204.3(11.1)$ & $203(11.3)$ & $202.6(11.4)$ & $201.9(12.2)$ & $199.2(11.1)$ & 2.896 & 0.02 & 0.01 \\
\hline $\begin{array}{l}1^{\text {st }} \text { Average Speed } \\
(\mathrm{km} / \mathrm{h})\end{array}$ & $185.1(10.3)$ & $184.0(10.5)$ & $183.0(10.6)$ & $181.3(10.1)$ & $180.7(10.7)$ & 4.730 & 0.001 & 0.02 \\
\hline $\begin{array}{l}2^{\text {nd }} \text { Average Speed } \\
(\mathrm{km} / \mathrm{h})\end{array}$ & $150.0(11.4)$ & $149.8(11.3)$ & $149.4(11.5)$ & $147.2(10.0)$ & $146.8(10.6)$ & 2.510 & 0.04 & 0.01 \\
\hline Return winner\% & $1.6(2.6)$ & $1.9(3.0)$ & $1.8(2.6)$ & $2.2(3.2)$ & $2.2(2.9)$ & 1.088 & 0.36 & 0.004 \\
\hline $\begin{array}{l}\text { Return unforced } \\
\text { error } \%\end{array}$ & $3.6(4.1)$ & $3.1(3.8)$ & $3.2(3.9)$ & $4.2(5.2)$ & $3.0(3.6)$ & 2.062 & 0.08 & 0.008 \\
\hline $\begin{array}{l}\text { Return } 1^{\text {st }} \text { serve } \\
\text { won } \%\end{array}$ & $26.6(12.8)$ & $28.2(14.2)$ & $26.9(13.3)$ & $29.6(13.4)$ & $28.2(11.7)$ & 1.592 & 0.17 & 0.006 \\
\hline $\begin{array}{l}\text { Return } 2^{\text {nd }} \text { serve } \\
\text { won } \%\end{array}$ & $48.3(16.9)$ & $49.3(17.5)$ & $49.5(16.4)$ & $50.1(17.9)$ & $52.1(16.2)$ & 0.736 & 0.57 & 0.003 \\
\hline $\begin{array}{l}\text { Break points per } \\
\text { return game }\end{array}$ & $0.6(0.5)$ & $0.6(0.5)$ & $0.5(0.5)$ & $0.6(0.5)$ & $0.6(0.5)$ & 0.392 & 0.82 & 0.001 \\
\hline Break points won $\%$ & $36.3(36.1)$ & $36(34.3)$ & $35.6(36.4)$ & $37.8(33.3)$ & $41.4(37.1)$ & 0.392 & 0.82 & 0.001 \\
\hline Break points saved $\%$ & $63.7(36.1)$ & $64(34.3)$ & $64.4(36.4)$ & $62.2(33.3)$ & $58.6(37.1)$ & 1.282 & 0.28 & 0.005 \\
\hline $\begin{array}{l}\text { Winner of total points } \\
\text { won } \%\end{array}$ & $32.0(11.7)$ & 33.7 (11.5) & $34.0(11.4)$ & $33.8(12.0)$ & $33.3(13.0)$ & 1.332 & 0.26 & 0.005 \\
\hline $\begin{array}{l}\text { Winner per unforced } \\
\text { error ratio }\end{array}$ & $1.1(0.9)$ & $1.4(1.6)$ & $1.4(1.5)$ & $1.3(1.1)$ & $1.2(0.9)$ & 0.518 & 0.72 & 0.002 \\
\hline Dominance ratio & $1.2(0.6)$ & $1.1(0.7)$ & $1.2(0.9)$ & $1.2(0.9)$ & $1.1(0.5)$ & 0.518 & 0.72 & 0.002 \\
\hline Net point won $\%$ & $65.4(23.9)$ & $65.0(22.5)$ & $65.0(23.1)$ & $62.8(23.1)$ & $65.6(25.1)$ & 3.923 & 0.004 & 0.014 \\
\hline $\begin{array}{l}\text { Net success of total } \\
\text { points won } \%\end{array}$ & $14.2(8.3)$ & $16.8(9.9)$ & $16.7(10.1)$ & $15.2(9.3)$ & $15.3(9.2)$ & 0.334 & 0.855 & 0.001 \\
\hline $\begin{array}{l}\text { Total distance } \\
\text { covered }(\mathrm{m})\end{array}$ & $640.4(241.4)$ & $658.5(250)$ & $630.7(253.4)$ & $623.2(260)$ & $653.3(267.3)$ & 0.704 & 0.589 & 0.003 \\
\hline $\begin{array}{l}\text { Distance covered per } \\
\text { point }(\mathrm{m})\end{array}$ & $10.3(2.7)$ & $10.7(2.9)$ & $10.3(2.9)$ & $10.2(2.8)$ & $10.6(3.2)$ & 1.047 & 0.382 & 0.004 \\
\hline
\end{tabular}



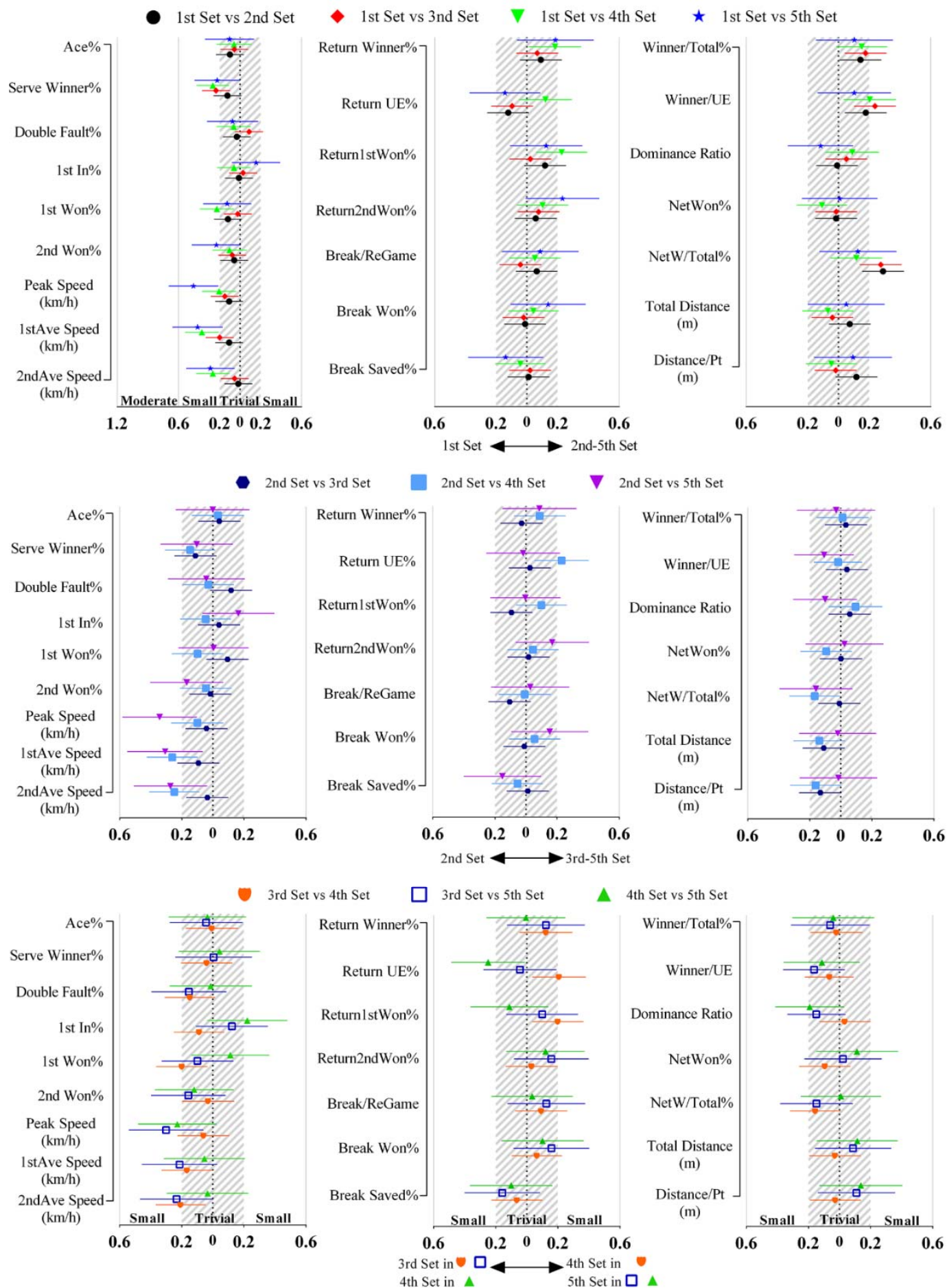

Standardized Differences in Means (Cohen) $90 \% \mathrm{CL}$

Figure 1

Standardized (Cohen) set-to-set differences of male players' match performance 


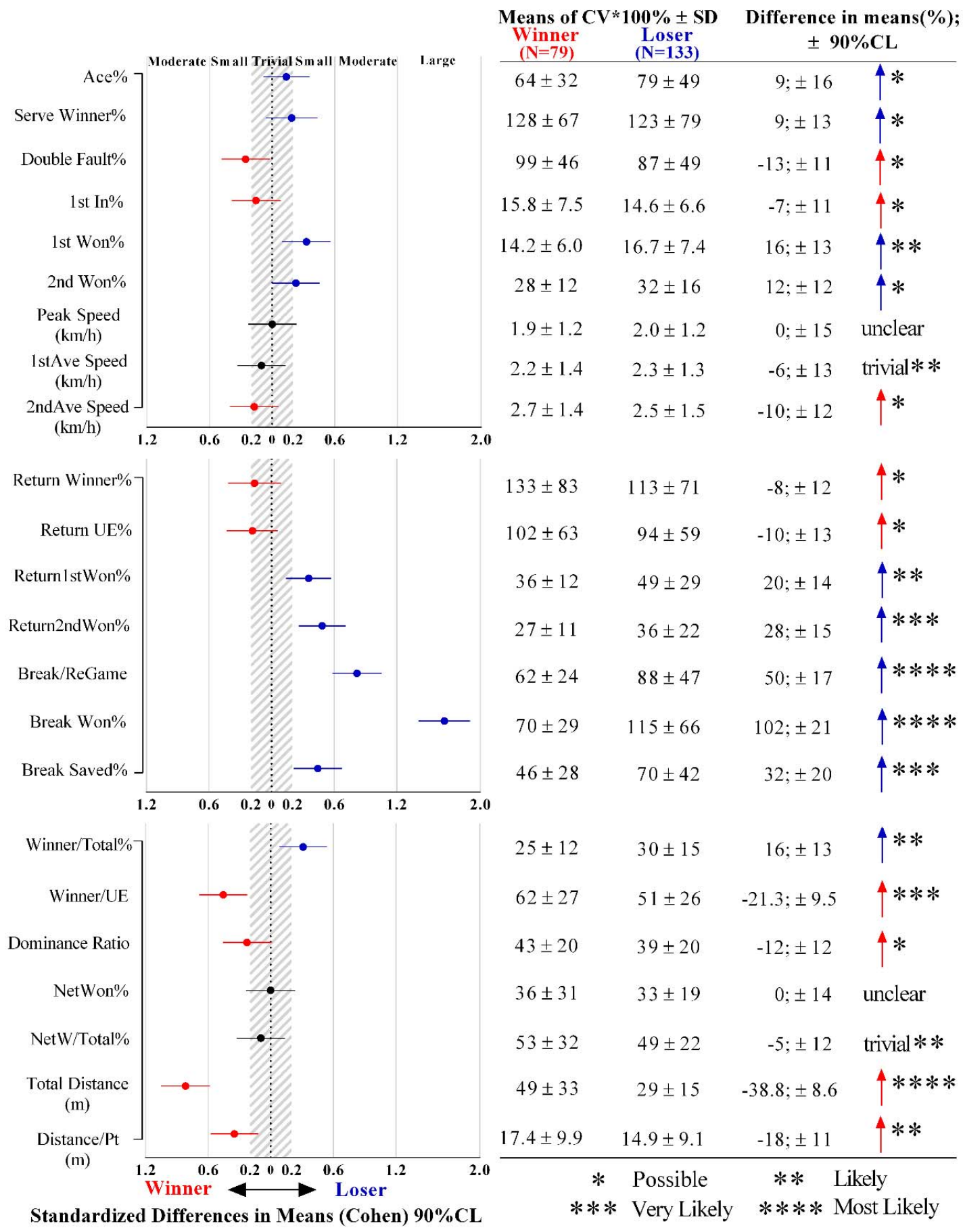

Figure 2

Descriptive statistics for the comparisons (standardized differences in Cohen's, differences in means in percentage and inferences of the true magnitudes for) of CVs of technical-tactical and physical performance variables between winning and losing players 


\section{Discussion}

This study analysed the differences in performance on a set-to-set basis for Grand Slam tennis players, and explored how winning players were differentiated from losing ones in performance stability under the effects of heavy match loads. Players experienced declines in the serve, net and running related performance and an increase in the return and winner related performance, as the match proceeded into the later sets. Furthermore, winning players were revealed to have a better consistency in most performance except for serve speed, net point, and running distance. The study provides evidence-based insight regarding the influence of fatigue within tennis matches, and helps inspect tennis players' behavior throughout the match, considering key performance indicators that lead to success.

Contrary to the previous findings that players could maintain constant serve performance over a five-set match in Wimbledon and were capable to overcome fatigue (Maquirriain et al., 2016), the current study found that not only players' serve performance, but also return and winner related performance underwent a decrease. Among those variables, serve speed turned out to be the most obvious one. The peak serve speed, 1st and 2 nd average serve speed all exhibited a gradual decrease from the first to the fifth set. As a result of decline in serve speed, players could not achieve the same number of serve winners. These findings would imply that professional players' performance was still impaired by match fatigue, and the disagreement between the current study with the previous one could be attributed to the differences in court surface. As Wimbledon is a fast-pace tournament played on a grass court, matches are finished in less time with fewer shot exchanges (Ma et al., 2013; O'Donoghue and Ingram, 2001). Therefore, players could get recovered from the last point and focus on their serving strategy, thus resulting in a constant serving behavior. However, as the hard-court surface in Australian Open and US Open is comparatively slower so that players had a lower shot rate and longer rallies, which would gradually induced players' fatigue. Moreover, playing in heat conditions might be another cause of decline in performance during Australian Open and US Open, considering that these two tournaments are scheduled in geographical regions (Melbourne and New York) where extreme weather conditions such as heat stress $\left(>35^{\circ} \mathrm{C}\right)$ and high relative humidity $(>50 \%)$ are prone to occur (Schranner et al., 2017; Smith et al., 2017). Indeed, it has already been reported that lower limb strength and physical performance of tennis players are impaired by the development of fatigue during match-play in the heat conditions (Périard et al., 2014). Consequently, given all the influencing factors, it is reasonable to infer that players could not maintain the same level of consistency in the serve like in Wimbledon matches.

Furthermore, players were shown to win more return points while making more return unforced errors in the last two sets than the initial sets. It is possible that due to the decrease in serve speed and serve winner caused by match fatigue (Gescheit et al., 2015), returners could own more time to prepare for a good return. Besides, as the match proceeded, players developed perceptual adaptation to their opponents' playing styles and preferences, which allowed them to anticipate the server's tactics. Consequently, returning players could tend to use more aggressive returning tactics in order to obtain the dominance in return game through opening up more angles, fast return to server's feet, or return and volley like the recent famous Sneak-Attack-by-Roger. Notably, compared to the fourth set, the reduction of return unforced error in the fifth set might imply that players chose a conservative returning tactic, and although being intuitive, we assume that under the high pressure of the last set, players tried to avoid losing easy points out of own returning mistakes in order to break server's games. However, as trivial differences were shown among all sets in breakpoint performance, it would mean that this tactic did not lead to better performance in returning games.

Possibly higher winners and net points were shown in the last sets, indicating that players built their game on active attacking either from baseline or going directly to the net to end the points. This was not only because they developed familiarity with opponents and match surroundings, but also played with more risks to shorten rallies as they faced limitations in physical capacity under consecutive days of highly 
intensive matches (Gescheit et al., 2016). Finally, only trivial to small differences in distance covered were shown among all sets, which might mean that players' physical performance was not impaired by the match duration and fatigue. Nonetheless, when relating it to the decrease in before-mentioned serve and winner related performance, it could be inferred that Grand Slam competitors still underwent heavy speed strength loads and muscle soreness during a prolonged match (Girard et al., 2006). Therefore, in order to improve the understanding of how players' match performance is affected by the effects of consecutive sets and how they modify their match-play accordingly, it is expected that future research could inspect closely the following aspects: serve and return directions and techniques, running directions, speeds and strokes speeds, net clearance of balls.

Winning and losing performance always captures research interests in performance analysis as it helps identify key performance indicators (Sampaio and Leite, 2013) that better discriminate between winners and losers as well as tailor the coaching process, setting concrete and practical goals in training and match preparation. To the best of our knowledge, the current research is the first study that investigated tennis players' variation in performance with such a complex manner. Results showed that winning players had more consistency in performance than losing players except for double fault $\%$, 1st serve in $\%$, 2nd serve speed, return winner\% and return unforced error\%, which represents the disparity between them in technical-tactical and physical capacities. On the one hand, higher variation in these variables implies that winners maintained an aggressive strategy throughout the match, and instead of reducing serve speeds and aiming for safer locations, they probably ran more risks in both first and second serves and returns to chase more angels (Whiteside and Reid, 2016b) and establish a similar level of dominance over opponents when serving within critical moments (Reid et al., 2016). On the other hand, it might be possible that they had clear arrangement of physical deposit and prioritized the serving and returning ability to avoid playing with precipitations and striking excessive numbers of rallies, which would accelerate the appearance of match fatigue (Ojala and Häkkinen, 2013).
Therefore, confirming the previous finding that the first and the second serve efficiency is key performance indicator for players (Cui et al., 2017; Reid et al., 2010), it is suggested that taking risks while guaranteeing a relatively lower variation in performance during service games is a critical predictor of winners and losers.

Furthermore, as winners presented higher efficiency and consistency in return games, they consequently obtained more breaking opportunities. At the same time, it is notable that losers presented higher variability in break point won $\%$ and break point saved $\%$. Obviously, these would again highlight the different returning capacity between the two groups. But it is also very likely that they were influenced by the match-status or score-line, as there were many situations where winners had such a great advantage that losing players might achieve none break point when returning. Similarly, it might occur that losing players failed to save the first break point when serving (O'Donoghue, 2012), whereas, to interpret the results from another perspective, we infer that winners could win or save stably more break points because they know that they were dominating the match and were motivated to win such critical points. In other words, lower variability of breaking performance would mean that winners were psychologically prepared and tactically resourceful (Cui et al., 2017; O'Donoghue, 2012). Future studies should consider the combined effect of match-scores, set scores and game-scores on player's returning performance.

Results showed that winners of the matches ran with a higher variation in distance when compared to losers. The identification of such perturbations in winners is a factor that has never been reported before in tennis, although it was found previously that winners ran more distance than losers during tennis matches (Carvalho et al., 2013). A possible explanation would be related to the spatial-temporal positioning stability between the two competing tennis players (Carvalho et al., 2013, 2014). Based on this theory, players would either move in the same direction or the opposite one and any break in this inter-player coordination started by one player would promote an abrupt positional change of another. Hence, it is inferred that winners would always try to take the initiative to 
move their opponents, causing more precipitations in their movements and preventing them from adjusting to the stroke rhythm. Considering that in each set, losing players also consistently adjusted themselves to the complex game status, and developed new tactical and perceptual adaptations, winning players had to modify the tactics in order to make opponents commit errors or to find better chances to terminate the points.

While the current study offers insights into professional players' set-based performance, there are some limitations that should be addressed. First, only playing performance in hard-court Grand Slams was considered and cautions should be taken when generalizing the findings to other surfaces. Secondly, detailed technical-tactical preferences of players were not analysed considering contextual variations such as match/set/game score-line and opponents' characteristics. Moreover, time-motion characteristics of players in relation to ball features (location, speed and angle) could not be included, which are fundamental for players to fully exploit the court space and optimize their decision-making.

As practical implications, it is suggested that: (i) fitness coaches should prepare a more representative physical conditioning program that would improve players' ability of fast recovery from a previous intensive work load. For example, some tennis-specific "high-intensity interval training" sessions could be prioritized and designed to improve the endurance and the physiological recovery rate of players during prolonged training or match time; (ii) technical coaches should help players optimize their net approaches and defensive tactics (when the opponents approach the net) while experiencing match fatigue. They could use the end of their training sessions (e.g. where logically players are tired) to deliberately practice either net approaches (e.g. when serving, when returning, when playing under critical points, etc.) or defensive tactics (i.e. lobs, passing shots, dropshots) and set up some punishments on players' failures in order to imitate the game-like pressure; (iii) while contrary to the last point, coaches should encourage players during hitting drills or a practice match to try to be more aggressive, and to take the initiative to move their opponents. For example, players could be awarded with "scores" every time their make offensive decisions, which are clearly confirmed by coaches. Afterwards, players could automatically win a point once their "scores" reach a certain sum. This will motivate players to always play positively and try to dominate the game. Finally, the current findings have also direct implications for less qualified or younger players who aspire to reach high competitive levels. By referring to professional performance, coaches could set achievable goals and design similar training drills as mentioned above, so that players could adopt better during their transition period.

\section{Conclusion}

In summary, the study revealed the influence of match fatigue on technical performance and tactical adaptation; and demonstrated that match winners played more consistently, yet they would sacrifice the stability in the second serve, winner, and physical performance to be more aggressive so that they could dominate the match. The results provide evidence-based information to advance the knowledge of elite players' match-play performance and game behavior. From a practical perspective, coaches are suggested to tailor specific training drills aimed to help players withstand prolonged matches and improve net approach and defense performance while experiencing fatigue.

\section{Acknowledgements}

This work was supported in part by National Key R\&D Program of P.R. China (2018YFC2000600). YC was supported by the China Postdoctoral Science Foundation and the Fundamental Research Funds for the Central Universities (2019QD033). 


\section{References}

Carboch J, Vejvodova K, Suss V. Analysis of errors made by line umpires on ATP tournaments. Int J Perf Anal Spor, 2016; 16(1): 264-275

Carvalho J, Araujo D, Travassos B, Esteves P, Pessanha L, Pereira F, Davids K. Dynamics of players' relative positioning during baseline rallies in tennis. J Sports Sci, 2013; 31(14): 1596-1605

Carvalho J, Araújo D, Travassos B, Fernandes O, Pereira F, Davids K. Interpersonal dynamics in baseline rallies in tennis. Int. J. Sports. Sci. Coa, 2014; 9(5): 1043-1056

Cowden RG. Competitive Performance Correlates of Mental Toughness in Tennis. Percept Motor Skill, 2016; 123(1): 341-360

Cui Y, Gómez M-Á, Gonçalves B, Liu H, Sampaio J. Effects of experience and relative quality in tennis match performance during four Grand Slams. Int J Perf Anal Spor, 2017; 17(5): 1-19

Cui Y, Gómez M-Á, Gonçalves B, Sampaio J. Performance profiles of professional female tennis players in grand slams. PLOS ONE, 2018; 13(7): e0200591

Cui Y, Gómez M-Á, Gonçalves B, Sampaio J. Clustering tennis players' anthropometric and individual features helps to reveal performance fingerprints. Eur. J. Sport Sci., 2019; 19(8): 1032-1044

Davey PR, Thorpe RD, Williams C. Fatigue decreases skilled tennis performance. J. Sports Sci., 2002; 20(4): 311-318

De Bosscher V, De Knop P, Van Bottenburg M, Shibli S. A Conceptual Framework for Analysing Sports Policy Factors Leading to International Sporting Success. Eur. Sport Manag. Q., 2006; 6(2): 185-215

Dube SK, Tatz SJ. Audience Effects in Tennis Performance. Percept Motor Skill, 1991; 73(3): 844-846

Filipcic A, Leskosek B, Filipcic T. Split-Step Timing of Professional and Junior Tennis Players. J Hum Kinet, 2017; 55: 97-105

Gescheit DT, Cormack SJ, Reid M, Duffield R. Consecutive Days of Prolonged Tennis Match Play: Performance, Physical, and Perceptual Responses in Trained Players. Int. J. Sport Physiol. Perform, 2015; 10(7): 913-920

Gescheit DT, Duffield R, Skein M, Brydon N, Cormack SJ, Reid M. Effects of consecutive days of match play on technical performance in tennis. J. Sports Sci., 2017; 35(20): 1988-1994

Girard O, Lattier G, Micallef J-P, Millet GP. Changes in exercise characteristics, maximal voluntary contraction, and explosive strength during prolonged tennis playing. Br. J. Sports Med, 2006; 40(6): 521526

Gomes RV, Coutts AJ, Viveiros L, Aoki MS. Physiological demands of match-play in elite tennis: A case study. Eur. J. Sport Sci, 2011; 11(2): 105-109

Hopkins W, Marshall S, Batterham A, Hanin J. Progressive statistics for studies in sports medicine and exercise science. Med Sci Spor Exer, 2009; 41(1): 3-12.

Hopkins WG. Measures of reliability in sports medicine and science. Sports Med, 2000; 30(1): 1-15

Hopkins WG. A spreadsheet for deriving a confidence interval, mechanistic inference and clinical inference from a P value. Sportscience, 2007; 11: 16-21

Hornery DJ, Farrow D, Mujika I, Young W. An integrated physiological and performance profile of professional tennis. Br. J. Sports Med., 2007; 41(8): 531-536

ITF. (2005). Line Calling Retrieved Nov 11, 2017, from http://www.itftennis.com/technical/technicalcentre/line-calling.aspx

Klaassen FJ, Magnus JR. Are points in tennis independent and identically distributed? Evidence from a dynamic binary panel data model. J Am Stat Assoc, 2001; 96(454): 500-509

Ma SM, Liu CC, Tan Y, Ma SC. Winning matches in Grand Slam men's singles: An analysis of player performance-related variables from 1991 to 2008. J. Sports Sci., 2013; 31(11): 1147-1155

Maquirriain J, Baglione R, Cardey M. Male professional tennis players maintain constant serve speed and accuracy over long matches on grass courts. Eur. J. Sport Sci., 2016; 16(7): 845-849 
Martinez-Gallego R, Guzman JF, James N, Pers J, Ramon-Llin J, Vuckovic G. Movement Characteristics of Elite Tennis Players on Hard Courts with Respect to the Direction of Ground Strokes. J. Sport. Sci. Med, 2013; 12(2): 275-281

Mecheri S, Rioult F, Mantel B, Kauffmann F, Benguigui N. The serve impact in tennis: First large-scale study of big Hawk-Eye data. Stat Anal Data Min, 2016; 9(5): 310-325

Morante SM, Brotherhood JR. Air temperature and physiological and subjective responses during competitive singles tennis. Br. J. Sports Med, 2007; 41(11): 773-778

Murray NP, Hunfalvay M. A comparison of visual search strategies of elite and non-elite tennis players through cluster analysis. J. Sports Sci., 2017; 35(3): 241-246

O'Donoghue P. Break points in Grand Slam men's singles tennis. Int J Perf Anal Spor, 2012; 12(1): 156-165

O'Donoghue P, Ingram B. A notational analysis of elite tennis strategy. J. Sports Sci., 2001; 19(2): $107-115$

Ojala T, Häkkinen K. Effects of the Tennis Tournament on Players' Physical Performance, Hormonal Responses, Muscle Damage and Recovery. J Sport Sci Med, 2013; 12(2): 240-248

Pereira TJC, van Emmerik REA, Misuta MS, Barros RML, Moura FA. Interpersonal coordination analysis of tennis players from different levels during official matches. J Biomech, 2018; 67: 106-113

Périard JD, Racinais S, Knez WL, Herrera CP, Christian RJ, Girard O. Coping with heat stress during matchplay tennis: Does an individualised hydration regimen enhance performance and recovery? $\mathrm{Br}$. $J$. Sports Med., 2014; 48(Suppl 1): i64-i70

Reid M, Duffield R. The development of fatigue during match-play tennis. Br. J. Sports Med., 2014; 48(Suppl 1): i7-i11

Reid M, McMurtrie D, Crespo M. The relationship between match statistics and top 100 ranking in professional men's tennis. Int J Perfor Anal Spor, 2010; 10(2): 131-138

Reid M, Morgan S, Whiteside D. Matchplay characteristics of Grand Slam tennis: implications for training and conditioning. J. Sports Sci., 2016; 34(19): 1791-1798

Sampaio J, Leite N. Performance Indicators in Game Sports. In T. McGarry, P. O'Donoghue \& J. Sampaio (Eds.), Routledge Handbook of Sports Performance Analysis (pp. 115-126). London: Routledge; 2013

Schranner D, Scherer L, Lynch GP, Korder S, Brotherhood JR, Pluim BM, Periard JD, Jay O. In-play cooling interventions for simulated match-play tennis in hot/humid conditions. Med Sci Spor Exer, 2017; 49(5): 991-998

Seifert L, Button C, Davids K. Key properties of expert movement systems in sport. Sports Med, 2013; 43(3): 167-178

Smith MT, Reid M, Kovalchik S, Wood T, Duffield R. Heat stress incidence and matchplay characteristics in women's Grand Slam tennis. J Sci Med Sport, 2017; 21(7): 666-670

Triolet C, Benguigui N, Le Runigo C, Williams AM. Quantifying the nature of anticipation in professional tennis. J. Sports Sci, 2013; 31(8): 820-830

Whiteside D, Reid M. External Match Workloads During the First Week of Australian Open Tennis Competition. Int. J. Sport Physiol. Perform., 2017; 12(6): 756-763

Whiteside D, Reid M. Spatial characteristics of professional tennis serves with implications for serving aces: A machine learning approach. J. Sports Sci, 2017; 35(7): 648-654

\section{Corresponding author:}

\section{Haoyang Liu}

AI Sports Engineering Lab, School of Sports Engineering,

Beijing Sport University, Beijing, China

Phone: +8615910751008

Email: liuhaoyang@bsu.edu.cn 